\title{
Idealistic Convention Center Using Cognitive Behavioral Techniques
}

\author{
Masoomeh Pakdell ${ }^{1}$, Farhad Kazemian ${ }^{2}$ \\ ${ }^{1}$ Department of Architecture, South Tehran Branch, Islamic Azad University, Tehran, Iran \\ ${ }^{2}$ Assistant Professor, Faculty of Arts and Architecture, South Tehran Branch, Islamic Azad University, Tehran, Iran
}

Email address:

masoomeh.pakdell@gmail.com (M. Pakdell), fkazemian8@gmail.com (F. Kazemian)

\section{To cite this article:}

Masoomeh Pakdell, Farhad Kazemian. Idealistic Convention Center Using Cognitive Behavioral Techniques. International Journal of Architecture, Arts and Applications. Vol. 2, No. 2, 2016, pp. 6-11. doi: 10.11648/j.ijaaa.20160202.11

Received: April 24, 2016; Accepted: July 4, 2016; Published: August 4, 2016

\begin{abstract}
In the communication field of psychology with architecture numerous studies have been accomplished, but in the field of behavioral psychology with urban design conference centers innovative and original are required for further researches. The main purpose of this article delves into how the compatibility and interaction of physical and psycho-social aspects of architectural space of its users by mannerss in physical environment design. To increase the interaction between humans in architecture space particularly in public spaces such as convention center which human spirit in it is the audience space must achieve the highest quality of space. In this paper, we present a model for ideal convention center, which is an advantage compared to the previous centers which have led to more satisfaction, sense of belonging of users, etc. that will be well detailed description thereof.
\end{abstract}

Keywords: Architecture, Behaviorism, Interior Design, Urban Areas, Convention Center

\section{Introduction}

An architecture is a constantly evolving and changing stream which has closely rooted in the past distant. Young architect requires a historical connection to these roots, but there are no institution and government neither across educational training nor course of a career that transfer the past architects' heritage and contemporary experiences to young generations and develop understanding of history in their minds (Has hemi, 2002: 3).

Many scholars have tried to define a comprehensive definition about architecture. Abu Ali Sina has shown in the introduction of al-Hudud: "It is obligatory to indicate the nature of the object's definition which mean its perfection essence. In such way that no cargo to its intrinsic spared and be actually or potentially involved." (Ibn Sina, 1988: 301).

Capon has gone into his two volumes entitled "Theoretical Foundations of Architecture" Relying on this statement of Aristotle's "Ethics treatise" that: "If we want to know what is a good man, first we must know what a man made of", to the set of contemporary architects' comments on the main components and categories of architecture (Capon, 2005:
353). Architecture is related to human environment as the most social art of human kind. We consider the following points along with the concept of architecture:

- Architecture is a creative act.

- Its idea is to form human habitat in all of its dimensions.

- Its scope encompasses a wide range of the response to the humanitarian needs, in connection with the environment and nature and even express emotions and his belief. Architecture manners is the science and dimensions of the building.

An architect definition is someone who Mansions' a lot and whom architects' and lead to excellence and mansion is meant prosperity as well. We use the definition of architecture presented by Vida Taghvaei as conclusion (Taghvaei, 2011: 84):

The following definition is the definition of "Common Architecture" before finding spatial life in the system which covers all arts except architecture. Which means each creation is dynamic and has a structure based on the ideas and values that due to cultural conditioning location and relying on present technology-innovative instruments and linguistic creativity of the artist is expressed; like poetry, 
music, sculpture, to be included. While in spatial framework which is the humans' habitat to realize the incidence of looks, covers itself by "architecture" garment. Perhaps the definition of "architecture is the mother of arts" is derived from this explanation.

\subsection{Research Objectives}

The main objective of this thesis delves into the areas of compatibility and interaction of physical space of architecture and psycho-social aspects of its users by solutions in design of physical environment. In order to achieve the stated objectives by creating desirable social relationships in architectural spaces and increasing social interactions and evaluating the effects and human and physical factors on socialization environment strategies to promote sociability environment can be reached.

To increase the interaction between humans in architecture space particularly in public spaces such as convention center which human spirit in it is the audience of space must reach the highest quality of space. Socialization process is the outcome of relationships. This relationship can connect people together or connect them with existing objects and furniture or indirectly through a relationship that objects create together.

The impact of this connection on individuals and their fascination and to be effective manners to gather people together. Socialization is a cultural transmission process and offers values and beliefs and relationship to the community through individual contracts. The overall goal of this thesis is as follows:

1. Design Convention Centre with behaviorist approach

2. The revitalization of public spaces using common interests and factors between people

3. Create a space toward enhancement of social interaction and sharing between people

4. Create a sense of belonging to place according to Iranian-Islamic architecture patterns

\subsection{Research Methodology}

Since topic is very useful in contemporary architecture thus, it is required to achieve the desired concepts and answers to original research questions. This research is applied and descriptive or non-experimental and survey services. Survey is to collect information about the convention center and the contact people in these centers.

Statistical Society refers to a population of persons or members which have at least one common trait and researchers' plans to use the survey results to apply on them. The study sample consisted of "a select group of research community which should have the features and characteristics of research community to allow its results to be generalized."

Statistical Society included all individual users of convention centers. To gather information about the background of the research and development of theoretical foundations and research, library resources available at the
National Library, research sites, and specialized books will be used. Available statistics are used to collect information.

\subsection{Behaviorism}

Behaviorism is a school of psychology that believes to recognize a living organism, checking his internal states like thinking is not required and only its external stimuli and behavior, such as crying is enough. This school, in the first half of the 20th century was one of the world's most influential poles in addition to psychology, the mind philosophies, linguistics and philosophies of that era had a profound impact. (Lattal and et al. 2003, Baum 2005);

Behaviorism is one of the philosophy trends that always tend to examine the behaviors that come to our minds rather than examining our thoughts and mental states. From the perspective of this tendency, no difference between two thinking can be made unless there is a difference in a manners that comes with the ideas. In a more precise definition, behaviorism offers following three claims about the mental states (Behaviorism, 2010; 30).

1. Psychology is the science of behavior. Psychology is not the science of mind (and mental states).

2. All our behavior can be fully explained and described without mentioning mental states (thinking) and our internal states. In other words, the source of our behavior is external (the environment) not internal (our ideologies).

3. The terms of mental states, that exist in terms of psychology must be: a) deleted and replaced with behavioral terms. Or b) translate to behavioral concepts.

These three propositions are three separated claim which each of them is form as a branch of behaviorism. The first claim is related to methodological behaviorists. The second proposition is related to psychological behaviorism and third proposition indicates logical behaviorist views (or analysis). We use methodological behaviorism approach in this paper and use it to connect to architecture.

Watson raises an objective psychology (behavioral science) and believes that it can be measured only by visible actions. He believes that the rules governing animal behavior is tru on humans as well. Behavior of the extremists were divided into two categories over time which is as follow:

\subsection{The Classic Behaviorism}

Classic behaviorism that emphasizes only to strengthen behavior by punishing and encouragement and has limited moral learning in the same way and has advanced slowly towards integrating with other theories, completion and more intricate.

\section{New Behaviorists}

These ideas eventually were divided into two major groups as follows:

- Patterns based on Action-oriented conditioning. 
- Patterns based on Cross-conditioning..

In general, some of the principles of behaviorism is as follow concluded. Principles of behaviorism is quite common to principles of proof-oriented.

1. Replace the philosophy of science rather than metaphysic;

2. The rejection of historicism and transactional;

3. Alternative relativity rather than appointed, and the average rather than rationality;

4. Change focus of the organization and structure to individual behavior;

5. Empirical assumptions rather than aristocratic and generalizations assumptions;

6. Rely on individuals' behavior instead of emphasizing the role of structures such as on the surface of a small group to the entire system;

7. Not being limited to deployment (as opposed to early positivist);

8. The importance of the judgment rather Supreme Assembly;

9. The use of mathematics and statistics and field research;

10. Avoid valuation;

11. Rely on sampling and measurement because of existence of possibility and accident

12. Order and harmony between theory and research and tools is pure scientific work.

In addition, a summary of behaviorism theory that is used in architecture is as we describe below and also explains important outlines that designers need to be bound by it.

Studer has stated use of conditioning factor principles in design of environments such as buildings in 1970, by looking at their behavior as behavioral regular learning systems to maintain specific topography, functional findings indicate that among other cases, the event has traditionally been seen as targets in the design process, For example, pleasance, exciting, convenience, likes or dislikes of users, which should be re-classified. This is not all the targets, but it means as a value that need to be treated skillfully direct orders better than all behavioral contexts.

In summary, based on Studer's idea can be concluded that the designer and consumer each has their own goal in which designers by using of identifying the behavior of consumers and available tools will achieve a better plan so that designer's intent and user's equipment can be each other's reflection and so on designer items can be consumer's targets.

- Some of behaviorism principles have potential applications in designing in order to change behavior.

- Considering our behavior in our activity environment before and after is useful insights for interventions design.

- Change in behavior does not necessarily happen in one step, but it is part of a forming continuous cycle.

- Recognition cannot be used as our understanding or search tool, users modeling gives a more valuable insights in terms of stimulus and response to designers.

- Positive and negative reinforcement and positive and negative punishment can be implemented through design features.

- Designer can help people and prevent a lot of social damages by looking at user's behavior.

- Considering manners and goal the possibility of a useful perspective in designing in order to change behavior would be provided, the purpose from a effectively user perspective is a mean that effect on the end of plan.

\section{Urban Area}

Rob Carrier (15: 1997) in the definition of urban area restricts all the perception values of urban spatial in the object itself that is the body of building's outside. But he also adds: "Each review of Aesthetic has a possibility of being based on personal taste", therefore different sensory habits of people in different time and place makes the beauty facts in urban area to be understood in various values. So that the more interest a society has for its history and take pride in itself, the more recognition goes for spatial values of its ancient city and gives courage to planners in order to use those former era treasures in today's work. On this basis, identify contacts of urban areas depends on their understanding and this is a subjective look to spatial values in the city.

Presumably, you can see both above looks have assumed urban area as "ISNA" and look like a two-dimensional image attached to the wall, in the event that whatever urban area is, the perception ability will be used and contacts movement will change. Zucker is of the opinion that the urban area is perceived by help of visualization that observer finds it through the extent and limits of space and a feeling of movement in it.

By the movement of observer in space, his different perception of sensory specially his sense of visual will be influenced and guided by the limits of its three-dimensional combination of space and structural lines. Therefore Zucker in quiddity definition of urban area defines it as an organized, decent and orderly structure which physically firmed for human activities and it is based on certain and clear rules. In his believes any empty gap between buildings does not count as urban areas but "Urban area" is about the understanding of contacts with his mental reserves of urban body which has been created in visual communication and movement.

\subsection{Different Kinds of Urban Areas}

Urban areas are the kinds of public open spaces in the city that are the social interactions infrastructure and has three main realm indicators of public areas of the city. The public, openness and social progress infrastructure (Pakzad, 2005). Urban areas divided into two types which are streets and square.

\subsubsection{Square}

Square is the first public area that humans have used of it for urban areas. Squares first came into existence in the western city complexes around open spaces and in front of 
the temples. This arrangement made possible emergence of a lot of prayers in outer space of temples where the "shrine" was defined and there was no let up for anyone apart from priests. This type of floor of the courtyard of the temples of Sumer was located in Mesopotamia to the Agora in ancient Greece, the Roman Forum, the late Christian and Islamic courtyard of the mosque frequently was found as symbolic values became proper examples for the presence of religious buildings. With this measure in which building was built around a central courtyard and the "atrium" was shaped as the space sample pattern for the future (Carrier, 17: 1997). But in the history of Iranian urban construction Square in front of the temple was so small that public participation in religious ceremonies was not possible and only the aristocracy and nobility were allowed to come into present in castle of Pars and Maad cities.

Square in the history of human civilization was the most influential urban area for social interaction and citizens of historic and new towns always know urban areas by separated open squares. Spatial square are for pause and rest which in the realm of public areas from yesterday to todayhave been developing a similar concept. Commercial square area, military parade ground, the ritual, the temple squares and city government center, outside mosques and shrines are all relics of the past centuries that gradually lost their first functionality and symbolic content and only remain as cultural heritage.

\subsubsection{Street}

Street is a dispersed settlement products of houses. The path that provided by street gives us access from the central square (total) to individual parts (parts). Street in terms of functionality has deeper features than square but square has more attractive space to spend more time to create communication between people. The architecture in background of the street can only be seen when passing, historic urban street layout is designed in scale of walking or carriages pass, thus it is appropriate for people leisure time and activities, while it is inappropriate in scale of motor vehicles. Streets are rarely able to act as an independent space. The streets in fact are a part of a network of cities and up to now have maintained their passage functional path and are location general passing and outing place.

In structure of Pars and Maad cities of Iran, market is the only place where people have found their social presence and to this day the market and sales are the most important centers for people in their social interactions.

\subsection{Perception of Urban Area in Iran}

To explore and understand the urban areas of Iran in ancient era we cannot be contented only to the idea of urban area by introducing Western theorists at the present. It is necessary to introduce accomplished studies in this field in the concept of "urban area" by comparison with the basic idea of the historical city plan begin this revelation by analyzing urban areas in ancient Iran according to identification of people in that time. Doctor Habibi (2000) discussed the process of urbanization, urbanism, urban development in Iran in three general terms. He believes that the structure and texture of the 9th century BC flux Up to 4 $\mathrm{BC}$ which means up to Alexander's invasion and the collapse, the early monarchy was in the shape of castle town of ParsMaad. Therefore Maad flux was City / authority and inspired by Mesopotamian city / hill, city / temple and a kind of Utopia dominated by the Iranian state-run and there is no space for social interaction in urban body. Lack of desire and social interaction between government and people had been continued during the Achaemenid period and city / authority gamers had no public and social interaction space but the market.

With the fall of the Achaemenid in the 3rd century BC, fundamental changes in the structure and texture flux or the city Seleucid period can be seen and that is the mixture flux and Powerful city of Pars with the Greek city government.

The genesis of new cities is due to democracy, aristocracy and the authority of the Kingdom of Persia puts forward a new way of urban area. Seleucid government allows city to be the expression of physical-spatial of Iranian aspirations by emphasizing on the body of their temple. On the other hand the first Iranian presence in social interactions, was places to achieve dominance in the sphere of influence to its surroundings. For the first time the concept of square in Iran takes place, this square because of its principle which mean is Agora was the center of cultural, commercial and administrative exchanges and because of its location in the temple of the city it can be called ideal city government.

Construction and organization of flux and new military cities and in the late 3rd century BC To the 7th century AD. (I Hijra) is in the form of flux Partian and kingdom of Parthia on one hand is the power state in compliance with the king and Iranian aspirations and on the other hand the government is Where the vote of the people and the elites in politics and government decisions are being used.

Partian Cities are circumference and a collection of markets, the remains of Hellenistic- Parsian city and still goes with the concept of the ideal city in Iran as far as the castle in of ideal cities recalls the Persian era.

\section{Centers of Public Presence}

Popular convention center or the center of public gatherings is a public place yet has recognized the public areas for processes and formal and informal relationships and interaction through dialogue between people and the government. These centers are considered to meet the cultural-social needs of the community and provide some suitable location and character befitting for meetings and conferences and seminars, and other collective and grass roots activities and a place for the establishment of public institutions and government agencies and non-governmental organizations and representatives of people.

Agora in ancient Greece was the most famous public area in urban structure. The main public square that is a gathering of people in the city occurred there. In the study of ancient 
cities of Iran especially in Sassanian cities also saw the presence of civil society and social spheres so Sassanid legislature was composed of representatives of the people and established in the name of Baharestan. Although the Iranian parliament's count as a pride and indicated the dedication of fans in the institutionalization of civil society on that era (Ibn-Sina, 1988).

With the advent of Islam in Iran the basis on the framework used in Sassanid has not seen a major change, although due to the influence of Islam, religious organizations and mosques have played an important role in the social system of the cities and with the Mongol invasion to Iran, the Iranian cities has suffered a irreparable destruction and damage to the development and urbanization process that such cities as Nishapur and Ray can be noted.

This situation continued until the Safavid state and from this time onwards urbanization flourished again, and two cities of Isfahan and Shiraz where were the capital of the Safavid and Zand kings have enjoyed more prosperity. In the definition of urban convention center, definition and exploitation of space is such an important matter. But urban gathering areas can be generally known as a part of urban social area that the city will be available to the public indefinitely. The aim of these centers beside the institutionalizationing of civil society, create the right conditions for communication between city authorities and the people so that can attract public participation in the affairs of the city and people find a sense of belonging to the city by contributing to the city's affairs. Then to clarify the definition of urban gathering places, we express the functions and features of these centers.

\subsection{Duties of Convention Centers in the City}

According to the definition stated in the Convention Center, we defined the tasks of the center as follow:

A) Contribute to group forming and strengthening of civil society in the city.

B) Create a place where people informed of the conditions of the city and can meet each other there.

C) City convention center is a place where help people meet their destiny and authorities in order to serve the people.

\subsection{Duties}

- Strengthening of civil society

- Notices

- Participation

- Identity

\section{Provide Innovative Manners}

As mentioned in previous sections, in order to achieve the perfect design for convention center user's behaviorism should be examined.

According to the studies mentioned before, we can conclude a convention center designer should have the following information:

1. Architecture Information

2. Identify and review existing convention centers

3. User's behaviorism information

The designer can start designing by having above information and therefore it is a community project of the convention center which will have many features and benefits including the following.

1. Citizens' satisfaction

2. Better relationship with the environment

3. More and deeper sense of belonging

4. Spirit improvement in some cases due the satisfaction of urban areas

5. Less missing, surplus and undefined spaces

Then a definite model conclusion for ideal convention centers designing will be offered.

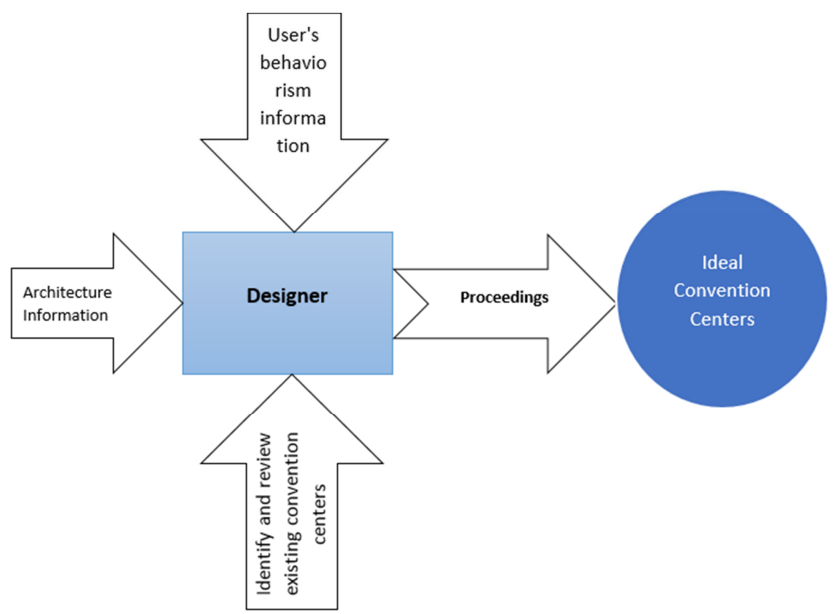

Figure 1. Proposed model for an ideal convention center design.

\section{Conclusion and Summary}

Behaviorism is known as a historical phenomenon, a series of interlocking doctrines and theories that have accumulated encircles the frailty of fundamental guidelines for ensuring the correct way to develop psychology science. Behaviorism, first of all, often associate with the principles and the metaphysical doctrine belief. There is less reluctance to discuss metaphysical problems contemporaneously than in the golden age of behaviorism and common philosophy revolution. Strengths of behaviorism are rooted in a commitment to pursue followers of this approach to replicable forms of analysis. Researchers often tries to show other researchers should generally achieve the same results that use the same set of assumptions records and evidence they employ. It needs to ensure that research findings can be repeated, necessarily means that behaviorists have to make clear the following way:

1. What they want to explain;

2. The theoretical explanation will achieve that development;

3. The manners in which empirical evidence is used to assess the theoretical explanation for the clarity of positions means that you no longer need them. 


\section{Acknowledgement}

This article is extracted from a Master's thesis entitled by Urban Conferences Center Design with Behavioral Psychology Approach by Masoomeh Pakdell from Supervisor doctor Dr. Farhad Kazemian from Islamic Azad University South Tehran Branch. This work was partly supported by Islamic Azad University South Tehran Branch.

We appreciate Scientific Committee and Jury of distinguished international journal of architecture, art and applications in accordance with the arbitration and valuable comments for this article.

\section{References}

[1] Ibn-Sina (1988). Al-Hudud or definitions, translated by Mohammad Mahdi Fooladvand, second edition, Tehran: Soroush.

[2] Amir Hosseini, Atie. Noqsan Mohammadi, Mohammad Reza. Forouzanfar Jalal. (2015), Urban Regeneration with behaviorist approach (Case Study: Tehran square of culture), the second Congress of Architecture, Restoration, Urbanism and sustainable environment.

[3] Taghvaei, Vida (2011). From quiddity to definition of architecture, Hoviat-e Shahr Publication, 5th year, No. 7.

[4] Habib, Farah. (2009). Iranian flux of urban areas, Journal of the Islamic Revolution Housing Foundation.
[5] Sajadzadeh, Hassan. Pirbabaei, Mohammad Taqi (2013). Event process in the urban area, architecture and urban utopia, No. 9.

[6] Rostamzadeh, Yavar. Rang Azma Azari, Mohammed. Naderi, Seyed Majid. Yeganeh Mansour. Mahmoudi Nejad. Hadi (2011). Assessment methods of citizenship behaviors in urban areas in the meta-analysis approach, Environmental Science and Technology, Volume XII, No. 3.

[7] Dolati, Marina (2012). PR and the school of behaviorism, scientific journal, specialized Public Relations Society of Iran, No. 78.

[8] Kashefi, Abd al Rasoul. (2009). Review philosophical behaviorism, theological philosophical Journal, (Journal of Qom University), No. 36.

[9] Kavianei Cherati, Ismaeil. Ghanbari Seyyed Kelaei, Reza. (2014), cultural monument with the approach of the Iranian identity (designed by people Case Convention Center), International Conference of Civil Engineering, Architecture and urban sustainable development.

[10] Capon, David Smith (2005). Theoretical Foundations architecture, translations doctor Ali Yaraan, volumes I and II, Tehran, Islamic Azad University, Science and Research.

[11] Gahl, Ian (2009). Living in the gaps between buildings, translation Shima Shasti, Tehran: SID. 